\title{
Ficções cosmopolitas: comunidades globais imaginadas na literatura brasileira do início do século XXI
}

\section{Cosmopolitan fiction: imagined global communities in 21st century brazilian contemporary literature}

\author{
Anderson Luís Nunes da Mata \\ Universidade de Brasília (UnB), Brasília, Distrito Federal, Brasil. \\ andersonmata@hotmail.com
}

Resumo: Os espaços geográficos pelos quais circula parte significativa dos personagens da ficção brasileira de princípios do século XXI são urbanos e internacionais. A publicação da coletânea de contos Granta em português - Os melhores jovens escritores brasileiros demonstra haver na escrita dos novos autores brasileiros a consolidação de um cosmopolitismo que, ainda quando visto a partir do que Silviano Santiago denomina o "perde-ganha da vida cosmopolita", isto é, das tensões com as histórias locais, celebra a ideia de uma "cidadania mundial". Essa ideia, por vezes desconsidera a quem se nega o direito a essa cidadania, ancorada agora mais na possibilidade de se percorrer e consumir espaços internacionais, que no humanismo cosmopolita socrático-kantiano. Se a nação é uma comunidade imaginada, como aponta Benedict Anderson, a comunidade global presente nas narrativas escritas por jovens escritores brasileiros também é uma forma de imaginar pertencimentos.

Palavras-chave: cosmopolitismo; localismo; literatura brasileira contemporânea; contos. 
Abstract: The geographic spaces crossed by great part of the characters of Brazilian fiction in the beginning of the 21 st century are urban and international. The short stories published in Granta em português - os melhores jovens escritores brasileiros shows the presence of some sort of cosmopolitanism in the writing of the new Brazilian authors, even when such attitude is seen through the lens of the "wins and losses of cosmopolitan life", according to the assertion by Silviano Santiago. It means that as from the tensions with local stories, the idea of a "world citizenship" is celebrated without taking into account the ones who are denied the right of enjoying such citizenship, which is now granted even by the possibility of being and consuming international spaces and not by the socratic-katian cosmopolitan humanism. If the nation is an imagined community, as Benedict Anderson points out, the global community in such narratives is also an exercise of imagining belongings.

Keywords: cosmopolitanism; localism; brazilian contemporary literature; short stories.

Recebido em 14 de março de 2015.

Aprovado em 20 de julho de 2015.

\section{Algumas considerações sobre o cosmopolitismo}

O termo cosmopolitismo, na contemporaneidade, guarda em seu conceito dois paradoxos principais. $O$ primeiro deles, diz respeito ao fato de que, ainda que evoque ideia de novidade, o termo remonta suas origens à antiguidade clássica. $\mathrm{O}$ segundo paradoxo está na própria etimologia da palavra. No grego, cosmopolita quer dizer "cidadão do mundo". Logo, a ideia contém, na oposição entre cidade e mundo, um dos binômios que definiram a modernidade: local-universal. É a partir dessa tensão que me proponho a pensar o modo como o cosmopolitismo tem sido retomado na narrativa brasileira contemporânea.

A aura de novidade ou de vanguarda que envolve a ideia de cosmopolitismo pode ter relação com o estranhamento que o conceito gera, em sua acepção original, e com os desdobramentos ao longo da história do pensamento ocidental. Esse estranhamento surge da 
expectativa de pertencimento a um local, e da consequente dedicação produtiva do sujeito a esse espaço, em um exercício de cidadania. $\mathrm{O}$ cosmopolita rompe com essa expectativa, demonstrando autonomia e fazendo uso de uma liberdade que é, antes de tudo, transgressão. É nesse sentido que o cosmopolitismo surge, na pólis grega, como uma atitude condenável, na perspectiva platônica, por exemplo; mas desejável, na perspectiva socrática - e executável nas experiências imperiais posteriores de Alexandre, de Roma e, à sua maneira, do cristianismo. Os desafios que surgem da possibilidade de uma atitude, e de uma práxis, cosmopolitas têm seus reflexos na gênese da modernidade. É aí, no contexto de estados nacionais fortes, que o cosmopolitismo emerge mais como miragem que como uma práxis possível. Ciente de que o conflito bélico para delimitação de fronteiras não coaduna com a ideia de uma cidadania mundial, Immanuel Kant prescreve, em seu À paz perpétua (2010), em linhas gerais, uma federação de nações - autorregulada e pautada pela busca da manutenção da paz.

Allen Wood aproxima o projeto de Kant das tentativas de se estabelecer comunidades internacionais na segunda metade do século $\mathrm{XX}$, seja por meio de organismos internacionais, organizações não governamentais, comunidades econômicas ou outras práticas de fundo transnacional (1998, p. 62). O termo comunidade aqui importa pelo fato de que essa utopia depende do sentimento de pertencimento que cada indivíduo nela incluído tem em relação ao conjunto. Nesse sentido, é interessante acompanhar a definição de Benedict Anderson para definir o fundamento da nação. Para ele, a nação é uma comunidade, é soberana e é imaginada. (Anderson, 2008, p. 32-5). Se o conceito de soberania não é pertinente nesse momento para pensar o cosmopolitismo (e é talvez na acepção do que é essa soberania que a atitude cosmopolita se distinga da nacionalista), o fato de esse mundo global ser imaginado é tão relevante para o cosmopolitismo quanto para a construção de uma identidade nacional.

O cosmopolita, não sem algum conflito, sente-se parte de uma aldeia global. E esse sentimento, evidentemente, embora horizontalizado, como define Anderson (2008, 35), não é universalizado do ponto de vista de classes: nem todos são cidadãos do mundo. De fato, essa é uma distinção reservada a poucos - normalmente, "os ricos e ociosos", como sublinha Silviano Santiago em "O cosmopolitismo do pobre" (2004, p. $62)$. 
A atitude cosmopolita entendida desde uma perspectiva eurocêntrica tem sido alvo de críticas por diversas correntes de pensamento contemporâneas. Dos nacionalismos marxistas às rupturas epistemológicas propostas por uma razão pós-colonial ou pós-ocidental, encontram-se possibilidades da construção de um pensamento, que tem na expressão literária, pelo seu caráter assumidamente subjetivo e local, seu ponto de inflexão. O cosmopolitismo é uma categoria operacional para se pensar a literatura exatamente porque ela própria se exprime a partir desse tensionamento entre o íntimo e o público; entre o nacional e o estrangeiro; entre o local e o global.

Os pressupostos políticos, éticos e estéticos desse modo de produzir conhecimento podem resultar no que Walter Mignolo chama de pensamento liminar (2003, p. 102), que é, na sua tensão entre localismo e globalidade, outra encarnação do cosmopolitismo - com uma atitude responsiva, não deslumbrada, em relação às pressões econômicas do capitalismo global.

\section{Uma comunidade internacional imaginada}

O sentimento de pertencimento a uma comunidade internacional, em suas diferentes feições, ganhou força, progressivamente, na literatura brasileira ao longo dos anos 1990. Não que essa não fosse uma preocupação dos escritores desde a literatura de informação, contudo há uma forma específica de encarar o global que emerge nas narrativas brasileiras em meio a esse contexto de abertura político-econômica dos anos 1980/90. É nessas décadas que temos consolidação da obra de João Gilberto Noll e de Ana Miranda, a consagração do romancista Chico Buarque e o surgimento da prosa de Bernardo Carvalho, por exemplo.

É também a década de 1990, que, em artigo publicado no caderno Ilustríssima, da Folha de S. Paulo, em fevereiro de 2014, Luciana Villas-Bôas denomina década perdida na literatura brasileira. O epíteto, usualmente atribuído aos anos 1980 em relação à economia, é transferido para a década seguinte pela agente literária, com base em uma análise do que ela chama de "divórcio da literatura brasileira com o público leitor". Para ela, uma nova geração de leitores, mais próxima dos códigos dos mass media, se afastou da literatura local, que não contemplava esses novos códigos, e se voltou para os best sellers traduzidos. Essa falta de um público local, que poderia ter como consequência a ruptura com a 
própria ideia de um sistema literário autônomo, é um dos argumentos utilizados por Villas-Bôas para criticar a postura do escritor brasileiro do início do século XXI.

"O autor brasileiro é vidrado numa tradução", ela afirma logo no início do seu texto. A provocação, pelo tom jocoso, é o ponto de partida para uma defesa de um cosmopolitismo ancorado no localismo. Para Villas-Bôas, é preciso fortalecer-se junto ao público nacional, para depois almejar a consagração em outros espaços nacionais. Presa à lógica das fronteiras nacionais, em consonância com o ponto de vista de uma agente de mercado, regido por leis de copyright que impedem a livre distribuição e circulação dos produtos, Villas-Bôas, com uma postura conservadora, chama os jovens escritores às falas: "Vá cuidar de seus leitores aqui, caro escritor, vá para a internet falar com eles, vá cobrar distribuição dos seus editores, vá conversar com jornalistas, vá ver se o que você está escrevendo é realmente bom - antes de cultivar o sonho colonizado e aprisionador do "sucesso no Primeiro Mundo", (Villas-Bôas, 2014).

Ao tratar das regras de mercado, a agente literária prescreve que os mercados estrangeiros buscam os autores que são sucesso de público em seu próprio país. A partir daí, acusa autores com tiragens pequenas no Brasil de trabalharem mais pelas traduções, ainda que em línguas e mercados "exóticos", que pela divulgação local de suas obras. Trata-se de argumento que invalida o anterior: os autores, então, não estariam em busca de consagração no "primeiro mundo", mas buscam tão-somente que suas obras atravessem as fronteiras nacionais.

O que parece escapar a Villas-Bôas é que essa ansiedade reflete um outro sentimento de pertencimento comunitário compartilhado por essa geração de escritores e da qual ela, talvez, esteja excluída. O próprio emprego do termo "primeiro mundo" e a dificuldade de compreender porque um autor com uma tiragem de mil cópias no Brasil buscaria uma tradução para uma língua com poucos falantes, como o sérvio, revelam o descompasso entre sua análise e o modo como esses autores se comportam.

É importante ressaltar que os jovens autores contemporâneos não formam um grupo coeso e homogêneo. Contudo, o alvo da crítica de Villas-Bôas talvez possa ser localizado no conjunto de jovens escritores selecionados para comporem uma antologia publicada na revista Granta em Português: os melhores jovens escritores brasileiros, lançada em 
2012. Ali, os autores, todos com menos de 40 anos no momento da publicação, formam, sim, um grupo coeso de homogêneo, do ponto de vista racial, de classe e de local de nascimento, como trataremos mais adiante.

Desse conjunto de escritores publicados pela Granta, João Paulo Cuenca foi quem respondeu, em artigo também publicado na Ilustríssima, ao artigo de Villas-Bôas. Em seu texto, Cuenca ironiza o fracasso anunciado da internacionalização desses jovens escritores: "Foi numa sala de embarque que li (...) [o] artigo de Luciana VillasBôas", ele afirma na abertura do seu texto. A partir daí, ele argumenta em favor de uma outra forma de pensar a internacionalização do escritor, fugindo da lógica mais conservadora do nacional. Primeiro, ele defende seu trabalho em relação à leitura, sem marcas acentuadas de engajamento:

O trabalho de arregimentar novos leitores -para mim e para a literatura brasileira- é um corpo a corpo ao qual tenho dedicado boa parte do meu tempo na última década, dentro e fora do Brasil. É o foco do meu trabalho? Não. Escrevo para isso? Não. Ganho dinheiro com isso? Aqui, pouco. No exterior, nenhum. Mas esses encontros ajudam a entender o que faço. E, ainda que entre a espetacularização da figura do escritor e uma difusão efetiva do hábito da leitura exista um abismo por trás de uma cortina de fumaça de boas intenções, com sorte ganho um ou outro leitor ao final dessas performances. Por isso, continuo. (Cuenca, 2014)

Em seguida, ele altera o eixo do binômio local-universal:

Cada leitor é tão importante quanto o próximo. "20 leitores locais são mais preciosos que uma edição na Bulgária"? Não. A não ser que a edição búlgara tenha menos de 20 exemplares vendidos. O "autor local", como Luciana Villas-Bôas gosta de chamar, escreve para o mundo, onde buscará seus leitores. Nem mesmo o seu país irá reconhecêlo se ele não tiver essa pretensão. (Cuenca, 2014)

Dessa forma, não é a busca por uma identidade com o leitor local que deve pautar a escrita (e o trabalho de mediação do autor). É, sim, uma pretensão cosmopolita: a de uma possível identificação com o mundo -e a de que seu texto faça parte dessa comunidade global imaginada. 


\section{Os limites da representação do cosmopolitismo}

Em seu conto publicado na Granta, "Antes da queda", Cuenca investe na construção de uma reflexão crítica sobre o cosmopolitismo, a partir de um narrador que ironiza as estratégias utilizadas na cidade para modernizar-se com vistas a uma internacionalização. Descrevendo o futuro do cenário urbano carioca, o narrador fala da cidade em relação ao mundo. Pessimista com a euforia em torno da pujança da economia brasileira e das perspectivas para a cidade do Rio de Janeiro, ele analisa esse cenário em contraste com experiências em outros espaços urbanos ao redor do mundo, como Barcelona, Miami, Londres e Nova Iorque. Sobre as transformações na cidade, o narrador afirma; "caminhava, então, em tempos pré-olímpicos, a tornar-se uma Barcelona um pouquinho mais miserável e bastante mais exótica". Porém, ao mesmo tempo em que essa comparação compreende um gesto analítico que dispõe a cidade do Rio de Janeiro nesse cenário internacionalizado e que, por estar marcado por cidades, e não países, ganha um contorno quase pós-nacional, focado em comunidades menores, ela também ajuda a elaborar juízos sobre o otimismo do carioca.

Esse otimismo surge singularizado no corretor de imóveis Tomás Anselmo, um dos dois personagens do conto, construídos no texto quase como exemplos ou tipos, não como sujeitos, uma vez que a voz do narrador se impõe para posicioná-los em um cenário em que uma estrutura política e, sobretudo, econômica, engessa sua atuação na narrativa. Nos juízos elaborados a partir do contraste entre o Rio e as demais cidades globais, o narrador acusa "o desejo provinciano de ser nova-iorquino nos trópicos, de emular cosmopolitismo através de uma cirurgia plástica urbana que jamais veio, mas que foi largamente estampada em infográficos nos jornais" (Cuenca, 2012, p. 43). Essa crítica dá a moldura para as comparações que ele próprio empreende nas suas análises, como o preço do aluguel em Copacabana e em Nova York (Cuenca, 2012, p. 43). Logo, se a princípio o narrador apresenta uma perspectiva que horizontaliza a relação entre as empreitadas olímpicas de Rio e Barcelona ou os processos de gentrificação da Rocinha e de Kreuzberg (Cuenca, 2012, p. 41-42), são invalidados no momento em que o próprio narrador trata como impossíveis as comparações, ridicularizando as ambições locais.

Em "O Rio sua", Tatiana Salém Levy seleciona o mesmo cenário - o Rio de Janeiro - porém, apresenta o cosmopolitismo da narradora 
desde uma perspectiva mais ingênua, sem dar espaço para a ironia. No conto, a narradora, ora incomodada, ora reencantada com a cidade que volta a percorrer ao retornar da Europa, chega a afirmar: "Adoro ver o mundo do alto. (...) Do morro da Urca (...) tenho a sensação de ser viajante e estar descobrindo o Brasil." O olhar exotizante sobre o espaço, que ela já apresentara no seu romance de estreia, A chave da casa, em relação ao estrangeiro, é repetido no conto em relação ao local: elementos da atmosfera natural - o calor, a umidade, a praia, os insetos - invadem a percepção da narradora.

Nos dois autores, trata-se, por um lado, de um cosmopolitismo strictu sensu, isto é, aquele que, em um espaço local marcado por diversos tipos de misérias, o acesso à porta de saída constitui-se como uma das principais marcas de distinção. Porém, em Cuenca, há ainda um cosmopolitismo de má consciência, no qual os problemas vividos na esfera local são mais complexos que as soluções emuladas por modelos estrangeiros de urbanização são capazes de sugerir, que é de onde emerge e ironia e a crítica dela decorrente, aspecto ausente no texto de Levy.

Os companheiros de antologia de Cuenca também investem em modos de representar o cosmopolitismo: a intercambista de volta ao Brasil de Carol Bensimon; os atletas-estudantes em Londres, de Emílio Fraia, a assassina de aluguel de Xerxeneski, o escritor em retiro na Europa oriental de Ricardo Lísias, além das memórias das ditaduras do Cone Sul de Julián Fuks e Miguel Castillo e, de modo mais sutil e sofisticado, o filho-irmão narrador do conto de Michel Laub. Nesse sentido, Granta pode funcionar como microcosmo de um cenário que é mais amplo e que inclui autores mais velhos (ou que ficaram de fora da antologia), como os já citados Bernardo Carvalho, Chico Buarque, Adriana Lisboa, Paloma Vidal, Elvira Vigna, Milton Hatoum, entre outros. Luis Augusto Fischer, na mesma Folha de S. Paulo, mapeou a revista, em artigo publicado ainda em 2012.

Segundo Fischer, "Pelos currículos, vê-se que os selecionados nasceram entre as classes confortáveis e vivem como escritores, editores, colunistas, críticos, tradutores, roteiristas -em suma, gente do meio letrado, em larguíssima maioria" (Fischer, 2012).

Esses aspectos levantados por Fischer coincidem com os dados de pesquisa coordenada por Regina Dalcastagnè, que identificou esse perfil nos autores de todas as idades publicados pelas principais editoras do Brasil entre 1990 e 2004 (Dalcastagnè, 2005, p. 31-33). Nesse sentido, 
Fischer acrescenta: "Pode-se perceber também uma outra similaridade: dos 20, apenas um não publicou por (nem trabalha para) editora carioca ou paulista, mesmo que alguns tenham estreado em editoras de outros Estados. Nada mais eloquente em matéria de concentração espacial: um filtro invisível opera o tempo todo na seleção."

A seleção, conduzida por escritores, críticos literários e professores de literatura, confirmou o filtro que já é feito pelo próprio campo literário. Ao que Fischer conclui:

A "Granta" parece ter fotografado um momento cosmopolitizante, antipovo e autorreferente, na geração mais nova, que surfa num mercado muito mais maduro do que jamais foi, em todos os níveis, na renda, nos circuitos de difusão, no consenso da importância da leitura. Olhando panoramicamente, duas linhas se mostram. Uma convergente: a economia brasileira de fato se volta para fora, como um "global player", e a nova geração se afina com isso. Outra divergente: a nação segue chafurdada em mazelas, como por exemplo a corrupção sistêmica, para não mencionar as enormes desigualdades sociais já quase invisíveis de tão antigas, mas a nova geração parece passar ao largo disso. (Fischer, 2012)

O conto de Laura Erber publicado na revista, "Aquele vento na praça", também traduz essa ansiedade pela internacionalização dos espaços da narrativa. No texto, a narradora viaja à Romênia, a fim de investigar a obra de um escultor. Marcado por referências a artistas (Neagu, Lars Von Trier, Franz Hellens e Balzac, por exemplo), espaços e instituições de diferentes origens, sobretudo europeias (Tate, Teatro Nacional de Bucareste, barragem de Vidraru, Gare du Nord) e por referências a países (Inglaterra, Romência, França), a jornada da protagonista é obscurecida pelas coordenadas que vão sendo despejadas no texto. Mais uma vez, o cosmopolitismo se afirma a partir de um agrupamento de referências nacionais. O que marca a internacionalização é a circulação de pessoas; não uma inflexão nos próprios modos de conceber os espaços. Nesse sentido, o narrador define o espírito da sua relação com o espaço: "a ideia de viajar rumo ao Leste num momento que nada me prendia a nada ou a ninguém ou a lugar algum parecia ótima" (Erber, 2012, p. 30). Esse insulamento do sujeito, desligado de qualquer vínculo comunitário, associado à liberdade de circular por qualquer espaço, sem as amarras 
do nacional, soa como um outro estágio em relação àquele da relação tensa entre o localismo e o cosmopolitismo, narrado desde a porta de saída, de Levy e Cuenca.

"O que você está fazendo aqui", conto de Luisa Geisler, é ainda mais exemplar dessa discussão. No conto, o narrador, empregado de uma multinacional, cruza o globo: de Porto Alegre a Hong Kong; de Munique a Canberra. Entre aeroportos, shopping centers (os convencionados nãolugares) e espaços marcados pelo afeto (lugares, em contraponto), como a casa da mãe ou o abraço da amante, o protagonista já parece não fazer diferença entre um país e outro. Ele não viaja para experimentar, mas se submete a uma imposição profissional. Sua atitude blasé com o trânsito internacional acaba por ser contrastada pela própria retórica da narrativa que pretende justamente contar a história desses percursos, sublinhando cada cidade onde o personagem chega, cada país por onde circula, cada língua em que se expressa. "Tá, eu viajo, conheço as coisas. E daí?", ele se interroga. No entanto, a narrativa deixa entrever, em seu efeito representacional, certo deslumbramento com essa possibilidade, pois é esse o seu tema, e é nele que estão investidos os recursos estilísticos do texto - do desenho do espaço à expressão multilíngue. Em outro fragmento, ele reflete "Ninguém pergunta as coisas para o auxiliar do pedreiro, mas todos os empregos se igualam". Ora, mas o conto não é sobre o auxiliar do pedreiro. É sobre o executivo globe trotter.

Retomando um último ponto do texto de Fischer, ele acusa esses "jovens escritores" de excluírem o político de seus textos. A afirmação é apressada e confunde "política" com "engajamento". Se suas narrativas são cosmopolizantes, elas também são, por consequência, politizadas; pois o gesto cosmopolita é uma inscrição política: um projeto de rearranjo dos pertencimentos, como espero ter ficado evidente na leitura do conto de Cuenca. O que falha, nos contos de Erber e, principalmente, de Luisa Geisler, é o fato de que a atitude de indiferença com relação aos localismos, como se tivessem sido apagados por uma internacionalização em que a comunidade imaginada abrange a todos, é um gesto de apagamento das diferenças, peça-chave de qualquer tentativa de ser cosmopolita, já que o cosmopolitismo é uma relação.

Mesmo dentro dessa lógica relacional, Silviano Santiago acusa o cosmopolitismo de ser fruto de uma noção paternalista e apaziguadora de multiculturalismo: aquela construída a partir de uma relação que apaga as diferenças ao absorvê-las de modo mais ou menos festivo. Em resposta, ele propõe uma outra forma de multiculturalismo, e de 
cosmopolitismo, que permita a emergência de diferenças e dos conflitos/ atritos que venham a reboque, como forma de "dar conta do influxo dos migrantes pobres nas megalópoles e resgatar o papel de grupos étnicos e sociais marginalizados no estado-nação" (Santiago, 2004, p. 59). Santiago, dessa forma, reafirma o papel do nacional, ou do local, sem cair no raciocínio simplista de que o cosmopolitismo, na sua encarnação contemporânea, deve obscurecer as particularidades locais e nacionais, ancoradas nas desigualdades sociais e no capitalismo global. Nesse sentido, o cosmopolitismo não deve necessariamente ser representado como nos contos de Levy, Erber e Geisler, centrado na esfera individual. Walter Mignolo identifica e critica esse individualismo como uma das razões pelas quais o cosmopolitismo se tornou um assunto importante na agenda de debates acadêmicos e políticos dos anos 1990 e 2000. Para ele, "as pessoas foram instadas a verem-se como cidadãos abertos do mundo, incorporando diversas identidades" (Mignolo, 2011, p. 260, trad. minha). Trata-se, então, de "uma concepção liberal de cosmopolitismo, nascida no século dezenove e agora traduzido em um ideal de cidadania cultural aberta e flexível" (Mignolo, 2011, p. 260, trad. minha).

Nesse sentido, a proposta de Mignolo soma-se à de Santiago, ao apontar que o cosmopolitismo, a fim de escapar de armadilhas como a do individualismo, "deve mirar no comum não à maneira de um modelo universal, mas como um conector universal" (Mignolo, 2011, p. 275, trad. minha). Desse modo, ele não pressupõe o cosmopolitismo como uma forma de homogeneização, mas de possibilidade de colaboração, a partir de uma perspectiva ética da práxis cosmopolita.

\section{Outro cosmopolitismo}

O resgate do aspecto ético do conceito, de feição kantiana, é também o que tem justificado o investimento da teoria e da crítica literária em sua direção. Ao defender o empoderamento desses sujeitos situados às margens das narrativas do multiculturalismo, Santiago também defende que eles possam expressar-se na linguagem do cosmopolitismo - hoje reservado a um grupo específico, que detém os meios legitimados de produção de discursos e narrativas. Para além desse embate entre centros e margens, a tensão entre o íntimo e o público pode fazer com que o cosmopolitismo surja de textos em que a internacionalização, entendida de modo mais literal como o trânsito entre países, não seja uma questão 
central. No conto "Animais", também publicado em Granta Michel Laub propõe esse tipo de tensionamento. Escrito em estilo fragmentário e acumulativo, o conto parte de uma cena (a encenação de Chapeuzinho Vermelho com o pai e o irmão da protagonista na plateia), que vai ganhando dramaticidade na medida em que a memória do narrador expande o episódio e estabelece uma relação com o leitor. A intimidade das relações familiares vai sendo exposta, o que ressignifica a cena teatral - uma apresentação pública - transformando-a numa metáfora para os silêncios contidos na relação entre pai e filho e para os ritos de passagem marcados pelo enfrentamento da morte.

Em dois dos fragmentos, o narrador chama a atenção para a ascendência judaica da família e para o passado marcado pelos campos de concentração nazistas: "Meu pai não frequentava a Sinagoga. Não participava de atividades beneficentes ligadas à comunidade. Não demonstrava interesse em temas religiosos" (Laub, 2012, p. 17) e "hoje me dou conta de que nunca conversei com meu pai sobre a infância dele, os colegas da escola que talvez tenham ficado na Alemanha, alguns ou todos indo parar em campos de concentração" (Laub, 2012, p. 17). Embora não sejam o ponto central do enredo do conto, essas informações acrescentam um estranhamento do narrador em relação ao pai que lhe é fundamental. A identidade cultural do imigrante, que pode facilmente ser conectada à do cosmopolita, nesse caso de um cosmopolitismo ligado ao trauma da guerra e do exílio, é negada pelo pai, que não frequentava a comunidade judaica, e pelo filho, que não se interessava, a princípio, pelo passado do pai.

A emergência desses temas nas memórias reconstituídas na narrativa, contudo, inscrevem a experiência do narrador além do nacional e das histórias locais em que se encontra inserido. A memória, enquanto espaço de configuração da representação, põe em funcionamento o princípio de colaboração apontado por Mignolo como uma saída para as armadilhas individualistas do cosmopolitismo. Portanto, no conto, a relação entre o que é mais íntimo (as histórias domésticas) e o que é público (a história que atravessa as biografias) garante que o problema do cosmopolitismo possa ser a moldura estrutural para a construção de um sentido (e de uma presença) na narrativa. Nesse sentido, como afirma Pierre Bourdieu, em As regras da arte, é na dissimulação sob os aspectos de aventuras contingentes, de acidentes anedóticos, de acontecimentos particulares, em uma forma sugestiva, alusiva, elíptica, que a literatura 
faz com que, como o real, o texto revele a estrutura, mas velando-a e furtando-a ao olhar (Bourdieu, 2002, p. 368).

Há, portanto, uma forma de fracasso (e de cansaço) no modo como os jovens autores tentam se provar cosmopolitas, o que poderia ser, talvez a sua marca geracional. Dessa forma, parece insuficiente, para a reflexão sobre o cosmopolitismo, a construção de personagens globe trotters, como nos contos de Erber e Geisler, que têm a representação do cosmopolitismo mais ligada à possibilidade de circular por diferentes espaços nacionais que propriamente pela construção de uma experiência internacionalizada. É quando a ironizam, como no caso de Cuenca, ou, principalmente, a inscrevem de modo mais complexo na forma do texto, evitando os lugares comuns da figuração do espaço internacional, como no caso de Michel Laub, que o conceito ganha força literária.

\section{Referências bibliográficas}

ANDERSON, B. Comunidades imaginadas: reflexões sobre a origem e a difusão do nacionalismo. Trad. Denise Bottman. São Paulo: Companhia das Letras, 2008.

BOURDIEU, P. As regras da arte: gênese e estrutura do campo literário. Trad. Maria Lucia Machado. São Paulo: Companhia das Letras, 2002.

CUENCA, J. P. “Antes da queda". In: Granta em Português: os melhores jovens escritores brasileiros, 2012.

CUENCA, J. P. O ornitorrinco e a agente literária. Folha de S. Paulo, Ilustríssima, São Paulo, 09/03/2014.

DALCASTAGNÈ, R. A personagem do romance brasileiro contemporâneo:1990-2004. Estudos de Literatura Brasileira Contemporânea, Brasília, n. 26, p. 13-71, jul./dez, 2005.

ERBER, Laura. “Aquele vento na praça". In: Granta em Português: os melhores jovens escritores brasileiros. Rio de Janeiro: Alfaguara, 2012.

FISCHER, L. A. “Letras em números: o que as estatísticas dizem sobre a 'Granta'”. Folha de S. Paulo, Ilustríssima, São Paulo, 02/09/2012.

GEISLER, L. 'O que você está fazendo aqui". In: Granta em Português: os melhores jovens escritores brasileiros. Rio de Janeiro: Alfaguara, 2012. KANT, I. Rumo à paz perpétua/ Zum ewigen Frieden. Trad. Heloisa Pugliesi. São Paulo: Ícone. 2010. 
LAUB, M. “Animais”. In: Granta em Português: os melhores jovens escritores brasileiros. Rio de Janeiro: Alfaguara, 2012.

LEVY, T. S. "O Rio sua”. In: Granta em Português: os melhores jovens escritores brasileiros. Rio de Janeiro: Alfaguara, 2012.

MIGNOLO, W. Histórias locais/Projetos globais. Trad. Solange Ribeiro de Oliveira. Belo Horizonte: Editora UFMG, 2003.

MIGNOLO, W. The darker side of western modernity: global futures, decolonial options. Durham \& London: Duke University Press, 2011.

SANTIAGO, S. "O cosmopolitismo do pobre". In: O cosmopolitismo do pobre. Belo Horizonte: UFMG, 2004.

VILLAS-BÔAS, L. "Para quem escreve o autor local?" Folha de S. Paulo, Ilustríssima, São Paulo, 23/02/2014.

WOOD, A. "Kant's project of perpetual peace". In: CHEAH, Pheng; ROBBINS, Bruce (Orgs.) Cosmopolitics: thinking and feeling beyond the nation. Minneapolis: University of Minnesota Press, 1998. 